\title{
Effectiveness and safety of isoniazid chemoprophylaxis for HIV-1 infected patients from Rio de Janeiro
}

\author{
Claudia Teresa Vieira de Souza ${ }^{1 /+}$, Yara Hahr Marques Hökerberg1', Sandro Javier Bedoya Pacheco', \\ Valéria Cavalcanti Rolla ${ }^{2}$, Sonia Regina Lambert Passos ${ }^{1}$ \\ 'Laboratório de Epidemiologia Clínica ${ }^{2}$ Laboratório de Pesquisa Clínica em Micobacterioses, Instituto Evandro Chagas, \\ Fundação Oswaldo Cruz-Fiocruz, Av. Brasil 4.365, 21045-900 Rio de Janeiro, RJ, Brasil
}

The clinical and epidemiological characteristics, adverse events, treatment adherence and effectiveness of isoniazid chemoprophylaxis were analyzed in a cohort of 138 tuberculosis/HIV-coinfected patients. An open, nonrandomized, pragmatic prophylactic trial was conducted on adult patients with a normal chest X-ray and positive tuberculin skin test $(\geq 5 \mathrm{~mm})$ who received isoniazid chemoprophylaxis $(300 \mathrm{mg} /$ day) for six months. The mean of follow up was 2.8 years (SD 1.3). Adherence to chemoprophylaxis was $87.7 \%$ (121/138). Only one patient presented tuberculosis after the end of chemoprophylaxis, corresponding to 0.3 cases per 100 persons per year. The relative risk of some adverse effects was 4.6 times higher (95\% CI: 1.9-11.5) in patients with positive anti-HCV serology (4/9, $44.4 \%)$ compared to those with negative serology $(12 / 129,9.6 \%)(p=0.002)$. This study provides evidence regarding the effectiveness and safety of a short and self-administered isoniazid regimen. We recommend the implementation of this routine by health service practitioners.

Key words: tuberculosis - chemoprophylaxis - isoniazid - HIV-1 - clinical trial (publication type) - treatment outcome

Infection with human immunodeficiency virus (HIV) represents an important challenge for the control of tuberculosis (TB). There were an estimated 8.8 million new cases of TB in the world in 2005 , with $80 \%$ of them occurring in 22 developing countries. Brazil currently has the 16th highest rate of new TB cases. A total of 1.6 million people died of TB worldwide, with 195,000 of them also being infected with HIV (WHO 2007).

Several studies have shown that TB chemoprophylaxis reduces the risk of the disease in HIV-infected patients with a positive tuberculin test (induration $\geq 5 \mathrm{~mm}$ in diameter) (de Pinho et al. 2001, Grant et al. 2005). One of the strategies to reduce TB among patients with HIV recommended by the World Health Organization (WHO 2007), American Thoracic Society (ATS 2000) and Centers for Disease Control and Prevention (CDC 2003) is the introduction of isoniazid (INH). In the present article, we use the term "TB chemoprophylaxis" since the guidelines of the Brazilian Ministry of Health (MS) for HIV-infected subjects recommend INH monotherapy for 6 months using a dose of $300 \mathrm{mg} /$ day (ATS 2000, MS 2007).

In Brazil, one study showed a 3.5 fold increase in the risk of TB in AIDS patients (de Castro Toledo et al. 2000), while another study concluded that TB chemoprophylaxis has an important impact on the survival of HIV-seropositive patients with a positive tuberculin test,

Financial support: PAPES 3, Fiocruz (2002/2003), FAPERJ (2004/2005), CRPHF (2004)

+ Corresponding author: clau@fiocruz.br

Received 1 September 2008

Accepted 3 March 2009 reducing the risk of TB by $38 \%$, irrespective of antiretroviral therapy (de Pinho et al. 2001). The use of both INH and antiretroviral therapy in HIV-infected patients is associated with a significantly reduced incidence of TB (Golub et al. 2007).

Prophylactic trials for TB chemoprophylaxis are still rare in Brazil, a fact supporting the importance of concrete data regarding the effectiveness and safety of this preventive strategy (de Castro Toledo et al. 2000, de Pinho et al. 2001, Golub et al. 2007). Thus, the objective of the present study was to describe the clinicalepidemiological and behavioral characteristics, adverse events, adherence to scheduled visits and prescriptions and the effectiveness of TB chemoprophylaxis in a cohort of patients coinfected with HIV and TB.

\section{PATIENTS, MATERIAL AND METHODS}

An open, non-randomized, pragmatic prophylactic trial regarding INH prophylaxis $(300 \mathrm{mg} /$ day $)$ for six months was conducted at the Evandro Chagas Clinical Research Institute (IPEC), Oswaldo Cruz Foundation (Fiocruz). The study was approved by the Ethics Committee of IPEC/Fiocruz (protocol 000011/009-02).

The target population consisted of patients of both genders, over 18 years old, coinfected with TB and HIV and followed up at IPEC. Included in the study were patients with normal chest X-rays who did not mention BCG re-vaccination and had a positive purified protein derivative (PPD)-tuberculin skin test (induration $\geq 5 \mathrm{~mm}$ in diameter) performed by a trained professional. The patients agreed to participate in the study and signed a free informed consent form. This cutoff point was established for HIV patients, following the recommendation of the Centers of Diseases Control and Prevention and of the MS guidelines (ATS 2000, MS 2007). 
Patients with TB confirmed before admission, altered aminotransferases levels (values 3 times above the normal limits) or a history of TB treatment within the last five years were excluded (ATS 2000, MS 2007).

The patients were followed up on an outpatient basis monthly for six months after the beginning of chemoprophylaxis and then once every six months for a maximum period of five years. Two standardized questionnaires (baseline and follow-up) were used for data collection. Variables of interest included sociodemographic data, adverse events and incidence of TB. The cumulative incidence of TB was used as an indicator of chemoprophylaxis effectiveness (Last 2001).

The rate of adherence to the medication was determined on each visit by counting the number of tablets ingested by the patient during the period ( 3 tablets/day for a total of 90 tablets/month). To guarantee a safety margin for cases of justified absence from a scheduled visit (for reasons of work), 120 tablets were supplied per month. The complete treatment comprised of 540 tablets. To increase adherence to the public health visit, tablets were counted monthly. Adherence to the medication was defined as the use of more than $84 \%(453 / 540)$ of the INH tablets according to the recommended regimen and completing six months of the prophylactic scheme without interrupting the use of INH for $\geq 30$ consecutive days (MS 2007). When the patient did not attend the scheduled visit, he/she was contacted by telephone or telegram to reschedule another visit. In addition, a telephone number for communication with the service was available. As encouragement, travel expenses were covered until 2006 when this resource ended. Irregular use (in days) of INH, such as partial interruption of the medication for less than 30 consecutive days by the patient's own decision was also recorded.

On the inclusion visit, all patients were submitted to laboratory and radiological exams, including chest radiographs, biochemical blood tests, liver function tests and serology for hepatitis B and C. Liver function tests were also performed in the third month and at the end of chemoprophylaxis to monitor possible hepatotoxicity (values 3 times above the normal limits) or adverse effects of the medication.

The public health visit (TB chemoprophylaxis) consisted of counseling regarding the epidemiological history and prevention of TB and encouragement of adherence to treatment for HIV/AIDS infection in order to promote healthy life habits, protection of the patient and his/her partners and prevention of AIDS-related opportunistic diseases.

Variables related to sociodemographic data, history of alcohol, tobacco and drug use, exposure to TB, adherence to the medication and drop out from TB chemoprophylaxis were submitted to a univariate and stratified analysis. Mean, median and measures of dispersion (standard deviation or interquartile range) were calculated according to the type of distribution for the continuous variables of age, time of HIV infection, liver enzymes, CD4 lymphocyte cells count, viral load and duration of interruption of TB chemoprophylaxis in days, according to the type of distribution. Some variables were catego- rized. For example, income was classified according to the number of Brazilian minimum wages (1 Brazilian minimum wage $=$ US\$170).

CD4 cell count and viral load were compared before and after chemoprophylaxis by the nonparametric paired Wilcoxon test. Mean aspartate aminotransferase (AST) and alanine aminotransferase (ALT) levels on the initial visit and at three and six months were analyzed by the Friedman test for comparison of three paired nonparametric samples, since the Kolmogorov-Smirnov test showed no normal distribution of these variables.

The relative risks for the development of adverse effects during chemoprophylaxis and their respective 95\% confidence intervals were calculated.

\section{RESULTS}

Between August 2002-April 2007, 162 patients were referred to the project and 138 of them (85.2\%) fulfilled the eligibility criteria. The mean age of the sample was $41( \pm 9.7)$ years, with a median of 40 years and the mean time since first HIV-positive test was 5.7 years (range: 2.4-10.1). Most of the patients included in the study were white $(53 \%)$, males $(65 \%)$, from the municipality of Rio de Janeiro (63\%), with a family income of more than three minimum wages $(56.5 \%)$

Twelve $(8.7 \%)$ of the HIV-infected patients had relatives who were in contact with known TB active cases. All the patients had been living in the city of Rio de Janeiro, where both TB and HIV are highly endemic (Golub et al. 2007). Among the patients studied, $92.8 \%$ presented a CD4 count $>200$ cells $/ \mu \mathrm{L}$ and in $47.8 \%$ viral load was undetectable $(<80$ copies $/ \mathrm{mL})$. Only 11 patients had been previously treated for TB at a mean interval of 10.4 years (7.2-14.3) before the beginning of TB chemoprophylaxis. Thirty three $(23.9 \%)$ patients reported to be allergic, 16 $(11.6 \%)$ reported previous gastrointestinal or hepatic disorder (gastritis, peptic ulcer, hepatitis) and $11(8 \%)$ had cardiovascular diseases or arterial hypertension. Nine $(6.5 \%)$ of the 138 patients presented positive serology for hepatitis $\mathrm{C}$ and one was positive for HBsAg.

At the beginning of the project, the mean diastolic (72.4 $\mathrm{mmHg}, \mathrm{SD}=9.7)$ and systolic $(115.0 \mathrm{mmHg}, \mathrm{SD}=14.3)$ blood pressures were normal and the patients presented a normal mean body weight $(70.2 \mathrm{~kg}, \mathrm{SD}=15.8)$. Tables I and II summarize the sociodemographic, behavioral and clinical-epidemiological characteristics of this cohort.

At the time of inclusion in the cohort, $74 \%$ of the patients were using antiretroviral drugs. The mean CD4 count was 539 cells $/ \mu \mathrm{L}(\mathrm{SD}=237$ cells $/ \mu \mathrm{L})$ and 562 cells $/ \mu \mathrm{L}(\mathrm{SD}=259$ cells $/ \mu \mathrm{L})$ before and at the end of TB chemoprophylaxis, respectively, with the difference being non-significant $(p=0.06)$. There was a significant reduction in viral load from $5.31 \log (10)[\mathrm{SD}=6.26$ $\log (10)]$ before chemoprophylaxis to $4.07 \log (10)[\mathrm{SD}=$ $4.59 \log (10)]$ after treatment $(\mathrm{p}=0.02)$.

The rate of adherence to TB chemoprophylaxis was $87.7 \%$ (121/138). Ten (7.3\%) patients definitely dropped out of treatment for various reasons. Fifty eight (42\%) of the 138 patients who started the study partially interrupted TB chemoprophylaxis, with half (27) of them interrupting treatment for one or two days per month, 


\section{TABLE I}

Characteristics of 138 patients co-infected with tuberculosis/ HIV who received tuberculosis chemoprophylaxis, IPEC/ Fiocruz, Rio de Janeiro, 2002-2007

\begin{tabular}{llr}
\hline Variable & & $\begin{array}{r}\text { Participants } \\
\mathrm{n}(\%)\end{array}$ \\
\hline $\begin{array}{llr}\text { Sociodemographic } \\
\text { Age }\end{array}$ & & \\
& & \\
Gender & Male years & $(70.3)$ \\
& Female & $42(29.7)$ \\
Family income & $\leq 3$ minimum wages & $90(65.2)$ \\
& $>3$ minimum wages & $60(34.8)$ \\
Race & White & $78(56.5)$ \\
& Mulatto & $73(52.9)$ \\
Educational level & Black & $33(23.9)$ \\
& $\leq 8$ years & $32(23.2)$ \\
Behavioral & $>8$ years & $66(47.8)$ \\
Alcohol consumption & & $72(52.2)$ \\
& & \\
& Socially & $73(52.9)$ \\
Current smoker & Alcohol dependent & $2(1.4)$ \\
Non injectable & Does not drink & $63(45.7)$ \\
drug use (current) & & $30(21.7)$ \\
\hline
\end{tabular}

\section{TABLE II}

Characteristics of 138 patients co-infected with tuberculosis/ HIV who received tuberculosis (TB) chemoprophylaxis, IPEC/Fiocruz, Rio de Janeiro, 2002-2007

\begin{tabular}{|c|c|}
\hline Variables & $\begin{array}{l}\text { Participants } \\
\text { n (\%) }\end{array}$ \\
\hline \multicolumn{2}{|l|}{ HIV exposure category } \\
\hline Heterosexual & $70(50.8)$ \\
\hline Homosexual/bisexual & $58(42.0)$ \\
\hline Blood transfusion & $9(6.5)$ \\
\hline Injectable drug user & $1(0.7)$ \\
\hline History of treated TB ( $>5$ years) & $11(8.0)$ \\
\hline History of TB chemoprophylaxis ( $>5$ years) & $17(12.3)$ \\
\hline Current household-active TB contact & $12(8.7)$ \\
\hline \multicolumn{2}{|l|}{ CD4 cell count at baseline } \\
\hline$<200$ cells $/ \mu \mathrm{L}$ & $10(7.2)$ \\
\hline$\geq 200$ cells $/ \mu \mathrm{L}$ & $128(92.8)$ \\
\hline \multicolumn{2}{|l|}{ Viral load at baseline ${ }^{a}$} \\
\hline$<80$ copies/mL [1.9 log $(10)]$ & $64(46.4)$ \\
\hline$<80-1000$ copies $/ \mathrm{mL}[3.0 \log (10)]$ & $15(10.9)$ \\
\hline $1,000-10,000$ copies/mL [3.0-4.0 log (10)] & $26(18.8)$ \\
\hline$>10,000$ copies $/ \mathrm{mL}[4.0 \log (10)]$ & $29(21.0)$ \\
\hline Childhood BCG vaccination & $120(87.0)$ \\
\hline Use of antiretroviral drugs for HIV & $102(74.0)$ \\
\hline $\begin{array}{l}\text { Side effects during TB chemoprophylaxis } \\
\text { (nausea/itchy skin/xerostomia) }\end{array}$ & $17(12.3)$ \\
\hline $\begin{array}{l}\text { Adherence to TB chemoprophylaxis } \\
\text { ( } 6 \text { months duration) }\end{array}$ & $121(87.7)$ \\
\hline
\end{tabular}

$a$ : missing 4 (0.7\%). mainly on the weekends, and reporting that they had forgotten the medication. The median time of partial interruption of chemoprophylaxis as the patient's own decision was four days (1.7-9.3 days) throughout the six months of treatment and two days (1-3 days) per month.

The patients continued to attend visits every six months in order to control the incidence of TB. Mean duration of follow up was 2.8 years (SD 1.3). There was no difference in the return rates for monthly visits based on travel reimbursement. None of the patients presented TB before admission or during the first 30 days of INH. Only one patient presented TB after the end of chemoprophylaxis, corresponding to 0.3 cases per 100 persons per year. This patient developed disseminated TB characterized by a diffuse interstitial infiltrate nine months after the end of TB chemoprophylaxis, which is associated with ganglionic TB. The patient was a 23 -year-old man, a flight attendant, who had regularly used $300 \mathrm{mg}$ / day INH within the recommended regimen and presented good adherence and no adverse events. At the beginning of chemoprophylaxis, the patient was known to be infected with HIV for four years, presented a CD4 count of 282 cells $/ \mu \mathrm{L}$ and a viral $\operatorname{load} 5.11 \log (10)$, and did not use highly active antiretroviral therapy (HAART). After the diagnosis of TB, the patient was treated with rifampicin, INH and pyrazinamide. The patient presented transient hepatotoxicity, which was reversed by clinical management, and was cured.

Temporary adverse events associated with TB chemoprophylaxis were observed in $17(12.3 \%)$ patients, with the most frequent events being nausea, pruritus and xerostomia lasting on average 3-5 days. Seven (5\%) of these patients required definite discontinuation of chemoprophylaxis, which, for two of the patients, was due to gastrointestinal intolerance starting during IPT chemoprophylaxis, and for five of the patients was due to hepatotoxicity. Of the latter five patients, three were receiving antiretroviral therapy, two had hepatitis $\mathrm{C}$ and one had hepatitis $\mathrm{B}$. The relative risk of developing any adverse events was 4.6 times higher (95\% CI: 1.9-11.5) in patients with positive anti-HCV serology $(44.4 \%)$ compared to patients with negative serology $(9.6 \%)(\mathrm{p}=0.002)$. The mean liver enzyme levels did not exceed the upper limit of normal at the end of INH treatment in the 121 patients who completed chemoprophylaxis (Table III).

Seven $(41.1 \%)$ of the 17 patients who reported the occurrence of previous adverse reactions to any medication also presented adverse events during TB chemoprophylaxis. The risk of developing adverse events during chemoprophylaxis was 4.9 times higher (95\% CI: 2.2-11.3) in patients who presented previous adverse reactions to any medication (41.1\%) compared to those who did not (8.4\%).

\section{DISCUSSION}

The challenge of controlling TB worldwide depends on the development of an adequate strategy to reduce the incidence of the disease in countries with a higher endemicity and in populations at a high risk of developing TB due to endogenous reinfection or due to the fact that they are contacts of TB patients, especially those coinfected with TB and HIV (ATS 2000, CDC 2003). 
TABLE III

Aminotransferase levels of 121 patients co-infected with tuberculosis /HIV who completed the tuberculosis chemoprophylaxis treatment, IPEC/Fiocruz, Rio de Janeiro, 2002-2007

\begin{tabular}{lccc}
\hline Aminotransferase & Median & 25-75\% range & p-value \\
\hline Aspartate aminotransferase (Baseline levels) & 23.0 & $18.0-31.8$ & 0.01 \\
(levels at 90th day of INH) & 25.0 & $20.0-33.8$ & $19.0-33.8$ \\
(levels at 180th day of INH) & 27.0 & $32.0-55.8$ & 0.05 \\
Alanine aminotransferase (Baseline levels) & 39.0 & $34.0-57.8$ & \\
(levels at 90th day of INH) & 42.0 & $35.0-56.7$ \\
(levels at 180th day of INH) & 43.0 & \\
\hline
\end{tabular}

With respect to treatment of HIV infection in Brazil, antiretroviral drugs are available free of charge, but this might not be sufficient to control HIV-related TB (Golub et al. 2007). Although various national and international studies have demonstrated the effectiveness of TB chemoprophylaxis (Santoro-Lopes et al. 2002, Woldehanna \& Volmink 2004, Whalen 2005, Moulton et al. 2007), its implementation has been limited (Grant et al. $2005)$. The reduction in the incidence of TB ranged from $55 \%$ for recurrent TB (Churchyard et al. 2003) and 46\% in patients without a history of TB (Grant et al. 2005) to $60 \%$ in a meta-analysis (Bucher et al. 1999).

The distribution of clinical-epidemiological characteristics in the present sample was similar to that reported in other Brazilian studies on TB chemoprophylaxis performed on an outpatient basis in TB/HIV-coinfected patients (de Pinho et al. 2001, Santoro-Lopes et al. 2002, Golub et al. 2007).

The adherence rate of the present sample was slightly higher $(87.7 \%)$ than those reported in a study conducted on $914 \mathrm{HIV} / \mathrm{TB}$-infected patients in Thailand, which was $84.5 \%$ when measured by self-report and $81.8 \%$ when measured by pill count (Hiransuthikul et al. 2005). As suggested in one study (Sebastian \& Bothamley 2000), one possible explanation for this difference is that adherence is higher among patients to whom knowledge, perception and discussion of TB are offered, as well as information regarding the importance of adhering to the six-month period of treatment, as done in the present study.

The drop-out rate $(7.3 \%)$ and withdrawal rate due to adverse events (5\%) were low when compared to a study carried out at 12 Spanish hospitals, in which $27 \%$ of 316 HIV-infected patients voluntarily abandoned chemoprophylaxis and $9.7 \%$ were withdrawn due to adverse events (Rivero et al. 2007).

In the present sample, the prevalence of adverse events was low $(17 / 138,12.3 \%)$, as expected since a systematic review conducted in 2004 showed that INH monotherapy is much less likely to require treatment interruption due to adverse events than multi-drug regimens (Woldehanna \& Volmink 2004, Elzi et al. 2007). An increase in liver enzymes has been described as a relatively frequent adverse event of INH treatment (Blumberg et al. 2005), which was observed in two patients of the present study who did not have hepatitis B or C. These results mainly show mild, clinically manageable adverse events and the absence of death or any interaction that may objectively impair follow-up parameters of HAART (CD4 and viral load) and are in agreement with the literature regarding the use of INH chemoprophylaxis (Gourevictch et al. 1999, de Pinho et al. 2001, Golub et al. 2007).

The prevalence of adverse effects was higher in patients with hepatitis C, a fact also demonstrated by Sadaphal et al. (2001), who observed hepatotoxicity associated with the use of INH in $22 \%$ of $146 \mathrm{HCV}$-positive patients.

In general, the incidence of TB is low in chemoprophylaxis studies. One cohort study described 11 cases of TB in 316 patients observed during a follow-up period of two years and the incidence of TB in the INH group was 3.5 cases per 100 individuals per year (Rivero et al. 2007). In another study, eight of $130 \mathrm{HIV}$-infected patients who received $\mathrm{INH}$ for nine months developed TB during a follow-up period of 43 months (Casado et al. 2002). Our study showed a lower incidence of TB, which might be explained in part by the small size of our sample and the high adherence. Selection bias was improbable because the patients were selected by trained professionals acording to the recommendation of the MS (MS 2007).

Limitation of the present study include monitoring the doses effectively taken as measured by self-report and pill count. However, a study carried out in South Africa showed that a negative screening result for urinary INH was associated with self-reported missed INH doses (Szakacs et al. 2006), suggesting the validity of this subjective but highly practical method.

Another limitation that must be considered is that BCG vaccination has a potential cross reactivity with the tuberculin PPD skin test. This study used the cutoff point of $5 \mathrm{~mm}$ as a positive PPD result, following the recommendation of the American Thoracic Society for HIV patients, for whom BCG immunization status should not be considered when implementing TB chemoprophylaxis (CDC 1996, ATS 2000). Although some studies have shown that BCG vaccination can influence PPD skin test results, this effect is more prominent in children and decreases after 15 years post immunization (Wang et al. 2002, Tissot et al. 2005). Furthermore, three studies, one in Brazil and the others in Gambia and Korea, showed that the prevalence of positive PPD results was similar among individuals with and without a BCG scar (Neuenschwander et al. 2002, Lienhardt et al. 2003).

Along the lines of this study, other short-duration regimens containing rifampicin and pyrazinamide initially recommended for the treatment of latent TB were later 
strongly discouraged by CDC guidelines (CDC 2003). These regimens should be reserved for patients who are not likely to complete a longer course of treatment and who can be monitored carefully (ATS 2000, CDC 2003).

The present study provides evidence regarding the effectiveness and safety of a short and self-administered INH regimen at daily doses for six months, which is recommended by the MS (MS 2007). Because of this recommendation, it was considered unethical to propose a group for comparison using another regimen of $\mathrm{TB}$ chemoprophylaxis.

Establish a short, self-administered TB chemoprophilaxis regimen is very important, considering the following observations: the main limitation of TB chemoprophylaxis is the poor completion rates for selfadministered therapy (de Pinho et al. 2001); the cost restrictions for directly observed therapy in countries with low per capita income without evidence of superior efficacy compared to self-administered treatment (Volmink \& Garner 2003); and the encouragement of studies regarding the cost effectiveness of the six-month INH regimen under local conditions (ATS 2000). We recommend the implementation of this routine by health service practitioners.

\section{ACKNOWLEDGMENTS}

To the patients participating in the project, to Mr. Jorge Luiz Nunes da Silva, Head of the Laboratory Diagnosis Service, Mrs. Itália Mazzei Portugal, Head of the Biochemistry Section, Dr. Ingebourg George, Head of the Immunodiagnosis Section, and Mr. José Liporage, Head of the Pharmacy Service, who contributed to the success of this project, and to the team of the "Tuberculosis Chemoprophylaxis Project": co-investigators: Brani Rozemberg, Sonia Maria Medeiros Ferraz Neves; collaborators: Aline Neves Camera, José Liporage, Noemi Pereira Lorenzi, Neuza Denise Bitencourt Leonardo, Renata Carla Nencetti Pereira, Belarmina Trindade Luz, Gilda Alcântara, Liliane Alves Reis, Marlene da Conceição Rezende.

\section{REFERENCES}

ATS - American Thoracic Society 2000. Target tuberculin testing and treatment of latent tuberculosis infection. Am J Respir Crit Care Med 161: S221-S247.

Blumberg HM, Leonard MK, Jasmer RM 2005. Update on the treatment of tuberculosis and latent tuberculosis infection. JAMA 293: $2776-2784$

Bucher HC, Griffith L E, Guyatt GH, Sudre P, Naef M, Sendi P, Battegay M 1999. Isoniazid prophylaxis for tuberculosis in HIV infection: a meta-analysis of randomized controlled trials. AIDS 13: 501-507.

Casado JL, Moreno S, Fortún J, Antela A, Quereda C, Navas E, Moreno A, Dondra F 2002. Risk factors for development of tuberculosis after isoniazid chemoprophylaxis in human immunodeficiency virus-infected patients. Clin Infect Dis 34: 386-389.

CDC - Centers for Disease Control and Prevention 1996. The role of BCG vaccine in the prevention and control of tuberculosis in the United States. MMWR Morb Mortal Wkly Rep 45: 1-18.

CDC - Centers for Disease Control and Prevention 2003. Update: adverse event data and revised American Thoracic Society/CDC recommendations against the use of rifampin and pyrazinamide for treatment of latent tuberculosis infection - United States. MMWR Morb Mortal Wkly Rep 52: 735-739.
Churchyard GJ, Fielding K, Charalambous S, Day JH, Corbett EL, Hayes RJ, Chaisson RE, De Cock KM, Samb B, Grant AD 2003. Efficacy of secondary isoniazid preventive therapy among HIV-infected Southern Africans: time to change policy? AIDS 17: 2063-2070.

de Castro Toledo AC Jr, Greco DB, Antunes CM 2000. Risk factors for tuberculosis among human immunodeficiency virus-infected persons. A case-control study in Belo Horizonte, Minas Gerais, Brazil (1985-1996). Mem Inst Oswaldo Cruz 95: 437-443.

de Pinho AM, Santoro-Lopes G, Harrison LH, Schechter M 2001. Chemoprophylaxis for tuberculosis and survival of HIV-infected patients in Brazil. AIDS 15: 2129-2135.

Elzi L, Schlegel M, Weber R, Hirschel B, Cavassini M, Schmid P, Bernasconi E, Ricknbach M, Furrer H, Swiss HIV Cohort Study 2007. Reducing tuberculosis incidence by tuberculin skin testing, preventive treatment and retroviral therapy in an area of low tuberculosis transmission. Clin Infect Dis 44: 103-104.

Golub JE, Saraceni V, Cavalcante SC, Pacheco AG, Moulton LH, King BS, Efron A, Moore RD, Chaisson RE, Durovni B 2007. The impact of antiretroviral therapy and isoniazid preventive therapy on tuberculosis incidence in HIV-infected patients in Rio de Janeiro, Brazil. AIDS 21: 1441-1448.

Gourevictch MN, Hartel D, Selwyn PA, Schoenbaum EE, Klein RS 1999. Effectiveness of isoniasid chemoprophylaxis for HIV-infected drug users at high risk for active tuberculosis. AIDS 13: 2069-2074.

Grant AD, Charalambous S, Fielding KL, Day JH, Corbett EL, Chaisson RE, De Cock KM, Hayes RJ, Churchyard GJ 2005. Effect of routine isoniazid preventive therapy on tuberculosis incidence among HIV-infected men in South Africa. JAMA 293: 2719-2725.

Hiransuthikul N, Nelson KE, Hiransuthikul P, Vorayingyong A, Paewplot R 2005. INH preventive therapy among adult HIV-infected patients in Thailand. Int J Tuberc Lung Dis 9: 270-275.

Last JM 2001. A Dictionary of Epidemiology, 4th ed., Oxford University Press, New York, 224 pp.

Lienhardt C, Fielding K, Sillah J, Tunkara A, Donkor S, Manneh K, Warndorff D, McAdam KP, Bennett S 2003. Risk factors for tuberculosis infection in the Sub-Saharan Africa: a contact study in the Gambia. Am J Respir Crit Care Med 168: 448-455.

Moulton LH, Golub JE, Durovni B, Cavalcante SC, Pacheco AG, Saraceni V, King B, Chaisson RE 2007. Statistical design of THRio: a phased implementation clinic-randomized study of a tuberculosis preventive therapy intervention. Clin Trials 4: 190-199.

MS - Ministério da Saúde 2007. [homepage on the Internet]. Recomendações para a terapia anti-retroviral em adultos e adolescentes infectados pelo HIV. Secretaria de Vigilância em Saúde/Programa Nacional de DST e Aids [updated 2008 April 13; cited 2008 May 6] Available from: (http://www.aids.gov. $\mathrm{br} /$ data/documents/oredDocuments/\%7BB8EF5DAF-23AE4891-AD36-553A3174\%7D/\%7B8CA22668-AE86-470E-BEC2 93661DBBDEA $1 \% 7 \mathrm{D} /$ consenso\%20-\%20adultos\%20adolescentes\%20infectados\%20hiv\%202006.pdf).

Neuenschwander BE, Zwahlen M, Kim SJ, Lee EG, Rieder HL 2002. Determination of the prevalence of infection with Mycobacterium tuberculosis among persons vaccinated against Bacillus Calmette-Guérin in South Korea. Am J Epidemiol 155: 654-662.

Rivero A, López-Cortés L, Castillo R, Verdejo J, García MA, Martínez-Marcos FJ, Díez F, Escribano JC, Canueto J, Lozano F, Pasquau J, Hernández JJ, Márquez M, Kindelán JM, Grupo Andaluz para el estudio de las Enfermedades Infecciosas (GAEI) 2007. Randomized clinical trial investigating three chemoprophylaxis regimens for latent tuberculosis infection in HIV-infected patients. Enferm Infecc Microbiol Clin 25: 305-310. 
Sadaphal P, Astemborski J, Graham NM, Sheely L, Bonds M, Madison A, Vlahov D, Thomas DL, Sterling TR 2001. Isoniazid preventive therapy, hepatitis $\mathrm{C}$ virus infection and hepatotoxicity among injection drug users infected with Mycobacterium tuberculosis. Clin Infect Dis 33: 1687-1691.

Santoro-Lopes G, de Pinho AM, Harrison LH, Schechter M 2002. Reduced risk of tuberculosis among Brazilian patients with advanced human immunodeficiency virus infection treated with highly active antiretroviral therapy. Clin Infect Dis 34: 543-546.

Sebastian MS, Bothamley GH 2000. Tuberculosis preventive therapy: perspective from a multi-ethnic community. Respir Med 94: 648-653.

Szakacs TA, Wilson D, Cameron DW, Clark M, Kocheleff P, Muller FJ, McCarthy AE 2006. Adherence with isoniazid for prevention of tuberculosis among HIV-infected adults in South Africa. BMC Infect Dis 6: 97.
Tissot F, Zanetti G, Francioli P, Zellweger JP, Zysset F 2005. Influence of Bacille Calmette-Guérin vaccination on size of tuberculin skin test reaction: to what size? Clin Infect Dis 40: 211-217.

Volmink J, Garner P 2003. Directly observed therapy for treating tuberculosis. Cochrane Database Syst Rev 1: CD003343.

Wang L, Turner MO, Elwood RK, Schulzer M, FitzGerald JM 2002. A meta-analysis of the effect of Bacille Calmette-Guérin vaccination on tuberculin skin test measurements. Thorax 57: 804-809.

Whalen CC 2005. Diagnosis of latent tuberculosis infection: measure for measure. JAMA 293: 2785-2787.

WHO - World Health Organization 2007. Global tuberculosis control: surveillance, planning, financing: WHO Report 2007. [monograph on the Internet]. [cited 2007 September 7]. Available from: (http:// www.who.int/tb/publications/global_report/2007/pdf/full.pdf).

Woldehanna S, Volmink J 2004. Treatment of latent tuberculosis infection in HIV infected persons. Cochrane Database Syst Rev 1: CD000171. 